\title{
Effects of Body Mass Index (BMI), demographic and socioeconomic factors on organized physical activity (OPA) participation in children aged 6-15 years: a cross-sectional study comparing primary and secondary school children in Greece
}

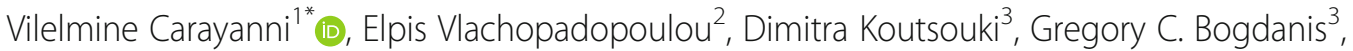
Theodora Psaltopoulou ${ }^{4}$, YannisManios ${ }^{5}$, Feneli Karachaliou ${ }^{2}$, Angelos Hatzakis $^{4}$ and Stefanos Michalacos ${ }^{2}$

\begin{abstract}
Background: The aim of the present study was to examine the influence of body mass index category, as well as of demographic and socioeconomic factors on the participation in organized physical activity (OPA) of schoolchildren attending primary and secondary school in Greece. Furthermore, to compare the difference between the two levels.

Methods: This is a cross-sectional study conducted on a representative elementary and secondary school cohort, derived using stratification and probability proportional to size (PPS) methodology. The final sample included 18,264 subjects, aged 6 to 15 years.

Parents of all students and students of secondary schools fulfilled validated questionnaires evaluating socioeconomic status, and participation to OPA. International Obesity Task Force (IOTF) cut offs were used to classify the children. Univariate and multivariate logistic models examined factors associated with OPA. All analyses were stratified by school level.

Results: Sport participation was not reported in 37.7 and $54.4 \%$ of primary and secondary schoolchildren respectively. Having BMl within normal range, being male, having parents participating in an organized activity and a high socioeconomic status seem to encourage participation in OPA in both school levels.

Conclusions: Children with normal BMI are more likely to participate in OPA. Parents as role model as well as higher socioeconomic status of the family emerge as important influencers. Participation in OPA declines as students enter secondary school. Interventions focusing on increasing physical education and activity into school daily program should be tailored to the specific needs of different weight categories and can possibly eliminate the impact of SES inequalities.
\end{abstract}

Keywords: Organized sports participation, Body mass index (BMI) category, Obesity, Primary and secondary schools, Socioeconomic status index (SES), Greece

\footnotetext{
*Correspondence: vkaragian@uniwa.gr

'Laboratory of Statistical Modelling and Educational Technology in Public and Environmental Health- sepeh.lab, Department of Public and Community Health, University of West Attica, 28 Saint Spyridonos str, 12243 Egaleo, Greece Full list of author information is available at the end of the article
}

(c) The Author(s). 2020 Open Access This article is licensed under a Creative Commons Attribution 4.0 International License, which permits use, sharing, adaptation, distribution and reproduction in any medium or format, as long as you give appropriate credit to the original author(s) and the source, provide a link to the Creative Commons licence, and indicate if changes were made. The images or other third party material in this article are included in the article's Creative Commons. licence, unless indicated otherwise in a credit line to the material. If material is not included in the article's Creative Commons licence and your intended use is not permitted by statutory regulation or exceeds the permitted use, you will need to obtain permission directly from the copyright holder. To view a copy of this licence, visit http://creativecommons.org/licenses/by/4.0/. The Creative Commons Public Domain Dedication waiver (http://creativecommons.org/publicdomain/zero/1.0/) applies to the data made available in this article, unless otherwise stated in a credit line to the data. 


\section{Background}

Low levels of physical activity and excessive sedentary time in childhood are associated with short and longterm psychological and physiological consequences $[1$, 2]. Physical inactivity, is an important factor that may contribute to low aerobic fitness, as well as to low energy expenditure, which may result in excessive weight gain [3]. In contrast, increased physical activity levels have been recognized as an important factor for the prevention and treatment of obesity [4]. Participation of young children and adolescents in organized sport training increases their physical activity level and contributes towards achieving the desired daily and weekly physical activity targets [5-8]. Furthermore, participation in competitive sports at club level, has been shown to increase the chances of reaching healthy cardiorespiratory fitness levels [9]. Organized physical activities (OPA) comprise exercise programs in specially designed areas, tend to require a coach or an instructor, are structured, and require payment [10]. Participation in OPA has been shown to be positively associated with proficiency of fundamental movements and physical fitness [11], because of the continuous guidance and errors correction by a coach/instructor and the latter's systematic structured content. Also, training exercises are individualized according to a person's abilities.

There is evidence that girls are less active than boys $[12,13]$. Additionally, socio-demographic factors such as age and geographic area (rural area),seem to constitute risk factors for non participation in OPA [14, 15].There is a number of studies showing that socioeconomic status, BMI category and family settings play an important role in regards to participation in OPA $[6,8,16,17]$. Another important factor influencing OPA may be the transition from primary to secondary school. This transition involves a significant life change and might be accompanied with a significant decrease in sport participation [18].

Thus, the aim of the present study was to examine the influence of BMI category, as well as demographic and socioeconomic factors on the participation in OPA in a large and representative sample of schoolchildren attending primary and secondary schools in Greece and compare the two levels.

\section{Methods}

\section{Sampling and participants}

The "Hellenic Action Plan for the Assessment, Prevention and Treatment for Childhood Obesity" was a school-based survey, financed by the National Strategic Reference Framework, conducted at a national level in Greece and provided the data that were used in the present analysis. Approval to conduct the study was granted by the Greek Ministry of National Education and the Greek Ministry of Health. Data were collected between $1 / 2015$ and $6 / 2015$. The study population comprised schoolchildren attending all grades of primary and secondary schools located in several municipalities in Greece (including rural areas and islands). Probability proportional to size (PPS) sampling was applied. The sampling of schools was stratified by the type of school, (primary or secondary), proportionally to the total number of pupils attending these schools. Following this procedure, an appropriate number of schools were randomly selected from each one of these municipalities, specifically, 278 schools, i.e. 205 primary and 73 secondary schools, were included. Prior to acceptance of children's participation to the study, an extended letter explaining the objectives of the study were provided to all parents or guardians whose children were attending these schools. Parents who approved participation of their children to the study have signed an informed consent. The response rate was $71 \%$ as 18,307 parents out of the 25,942 who signed parental consent forms have fully completed the questionnaire. After examination of univariate statistics to detect any anomalies [19] in the distribution of variables, (especially outliers or missing values 10 values on the total), aberrant values and duplicates (33 cases on the total), the total study sample in this analysis included 18,264 children aged between 6 to 15 years, who had complete physical activity data. The larger part of this sample ( $72.0 \%$ or 13,119 children) were primary school pupils, (ages 6-12), while 5145 (28.0\%) were secondary school (ages $12-15$ ) pupils. Pupils with severe chronic illnesses i.e. malignancies, diabetes mellitus, rheumatoid arthritis or systemic lupus erythematosusor receiving chronic therapies for more than 6 months per year for any diagnosis, were excluded from the analysis (70 children in primary schools and 43 children in secondary schools).

\section{Measurements}

Anthropometric measurements were conducted by sixteen health professionals, specially hired and trained for the purposes of the present study. Children were measured by two trained members of the research team. The protocol and equipment used were common in all schools. Each child was measured three times, and the average of the three measurements was computed. Body weight was measured to the nearest $100 \mathrm{~g}$ using a Tanita digital scale (Tanita BWB 800MA). Pupils were weighed without shoes with minimal possible clothing. Height was measured to the nearest $0.1 \mathrm{~cm}$ using a commercial stadiometer (Charder HM 200P Portstad). The Charder stadiometer was standardized against a Harpenden portable stadiometer. During the measurement of height, each pupil was standing barefoot, keeping shoulders in a relaxed position, arms hanging freely and head aligned 
to the Frankfort horizontal plane. Body weight and height were used to calculate BMI, using the Quetelet's equation, i.e. body weight $(\mathrm{kg}) /$ height $^{2}\left(\mathrm{~m}^{2}\right)$. BMI was calculated and subsequently participants were categorized according to the IOTF criteria [20] into the following four BMI categories: Underweight, Normal, Overweight and Obese. Both interrater and intra-rater reliability, measured with the intraclass correlation coefficients yielded values greater than 0.97 .

\section{Measures}

Three structured questionnaires were developed and administered to the parents and students. In elementary school the parents filled the questionnaires and in high schools two different questionnaires were answered by the students and the parents respectively. Validity and reliability of the three questionnaires was tested and found to satisfy the principles of reliability and validity [21]. In order to assess reliability and validity, prior to initiation of the study, data were collected from 450 parents of children aged 6-12 $\left(n_{1}\right), 450$ parents of children aged 12-15 $\left(\mathrm{n}_{2}\right)$, and 250 adolescents aged 12-15 $\left(\mathrm{n}_{3}\right)$, from the region of Attica. Exploratory factor analysis (EFA) was performed and Confirmatory Factor Analysis (CFA) followed in another sample $\left(\mathrm{n}_{1}=163, \mathrm{n}_{2}=163\right.$, $\mathrm{n}_{3}=93$ ) from 3 different regions to verify the factor structure. Cronbach's alpha $(\alpha)$ and Intraclass Correlation Coefficients (ICC) were used to test reliability. EFA results support the factorability of the correlation matrix. (Kaiser-Meyer-Oklin: 0.941-0.944 and Bartlett's test of Sphericity $<0.001$ in all cases). CFA revealed that the final models (6-factor models for parents and 5-factor models for adolescents) provided the best fit for our samples (RMSEA: 0.04-0.05 and CFI:O.90-0.94). Cronbach's alpha and ICC showed acceptable reliability ( $\alpha$ : $0.79=0.90$ and ICC:>0.67-0.91). All questionnaires were granted clearance by the Hellenic Data Protection Authority. The factors addressed included sociodemographic characteristics, such as socio-economic status, age, gender, geographic area (urban, semi urban, rural),and OPA habits. Semi-urban population includes the population of municipalities and communities, whose most populous settlement has 2000-9999 inhabitants, except those belonging to urban planning.

SES index is a score that characterizes socioeconomic status. It is derived by the combination of 5 factors, precisely, mother's and father's years of education, number of cars, rent or owned house and surface area of residence per number of inhabitants, composing the SES index that has a range between of $0-13$, with higher values indicating higher SES of the family.as previously published by Moschonis et al., 2013 [22].

With regard to the participation in OPA which is the outcome of the present analysis, a special section of the questionnaire addressed the participation in out-ofschool organized sports activities defined as structured in organized athletic facilities under the auspices of the state, athletic federations and sports and athletic clubs officially registered in the General Secretariat for Sports, that belongs to the Greek Ministry of Education.

\section{Statistical analysis}

The outcome of the study was the prevalence of children participation in OPA, in relation to BMI category, socioeconomic factors, and different socio-demographic variables. For the purpose of analysis, the variable "OPA" was dichotomized as "Yes-participated in organized team or individual sports at least twice per week" and "No-did not participate in organized teams or individual sports at least twice per week since September of the current school year". Examples were basketball, football, volleyball, swimming, dance, aerobics martial arts tennis, track and field and other. Due to the sampling procedure described above, the present data yield robust estimates of the prevalence of the four BMI categories in this cohort. Therefore, the prevalence is reported together with its $95 \%$ confidence intervals (CI).

Descriptive statistics were performed. Also, the $x^{2}$ statistical test and the Mann-Witney test were used to test the homogeneity between primary and secondary schoolchildren in variables of interest. Two-step cluster analysis procedure was done to explore SES grouping of participants [22]. Number of clusters was limited to three (high, moderate, and low SES). Univariate and multivariate logistic models were used to examine the association of the above mentioned factors with OPA, by school level.

The variables found, by use of univariate analysis, to be associated with the outcome variable at the $p<0.10$ level were included in the initial models to determine which factors were independent predictors of the outcome variable in the study subjects. Sandwich Variance Estimators were used in order to provide a consistent estimate of the variance-covariance matrix of parameter estimates [23]. A full model with main effects was fitted, and backward elimination was used to obtain a reduced model. The variables associated with the outcome variable at $<0.05$ level were maintained in the final models. Information criterion tests such as Akaike Information Criterion (AIC) and Bayesian Information Criterion (BIC) are used to compare models and select the better fitted model [24, 25].

All analyses were stratified by school level comparing primary and secondary schools. The results were recorded as frequencies $(\mathrm{N})$ and percentages, means and standard deviations (SD), unadjusted and adjusted, odds 
ratios (OR) with $95 \%$ confidence intervals $(\mathrm{CI})$, and $p$ values.

Statistical analyses were carried out using SPSS (IBM SPSS Statistics Version 23) and R language (Version 3.2.3).

\section{Results}

\section{Sample characteristics and SES results}

Missing values do not surpass $10 \%$ in any variable measured. Descriptive and inferential statistics for the distribution of socioeconomic and demographic variables in our sample are given in Tables 1 and 2. As can be seen (Table 1), the mothers of primary schoolchildren presented in general a higher educational level than those of secondary schoolchildren $(p=0.04)$ and the primary schoolchildren families presented a higher household size $\left(\mathrm{m}^{2}\right)$ per family member $(p<0.001)$. No significant differences were observed between primary and secondary schools in any other SES variables. Clusters distribution is presented in Fig. 1: The largest cluster that represents the medium SES (mean: 6.9, SD: 0.6) has
$60.3 \%$ of the clustered cases $(58.0 \%$ for primary schools and $66.2 \%$ for secondary schools). Also, the mean SES was significantly higher $(p<0.001)$ in primary schoolchildren families (mean: 6.9, SD: 1.6) compared to secondary schoolchildren families (mean: 6.6, SD: 1.5).

The prevalence of participation in OPA (Table 2) was 57.6\% (95\% CI: 55.4-59.7\%). More analytically, the prevalence of participation in OPA was $62.3 \%$ (95\% CI: $61.3-63.7 \%)$ in primary schools and $44.6 \%$ (95\% CI: 42.7-47.4\%) in secondary schools, reflecting a dramatic decrease in OPA participation from primary to secondary school and these differences were highly significant $(p<0.001)$ (Table 2). Fifty five percent of the children (58.0\% in primary and $48.0 \%$ in secondary school children) who reported participation in an OPA, practiced sports in Sports Clubs, $16.0 \%$ (13.0\% in primary and $23.0 \%$ in secondary school children) in a Gym, and $14.0 \%(13.0 \%$ in primary and $15.0 \%$ in secondary school children) inprograms organized by the municipality. Also, significant differences $(p<0.001)$ were detected in BMI categories between primary and secondary schools,

Table 1 Descriptive statistics and tests results for socioeconomic status (SES) in children aged 6-15 years $(N=18,264)$, by School level (ptimary and secondary schoolchildren)

\begin{tabular}{|c|c|c|c|c|}
\hline Socio-economic status variables & Total N(\%) & Primary schoolchildre N(\%) & Secondary schoolchildren N (\%) & $P$-value \\
\hline \multicolumn{5}{|l|}{ Years of Paternal education } \\
\hline$<9$ years & 1830(7.60) & 1146(10.10) & $684(15.70)$ & \multirow[t]{4}{*}{$0.33^{* *}$} \\
\hline $9-12$ years & $8499(56.60)$ & $6145(54.10)$ & $2354(54.00)$ & \\
\hline $12-16$ years & $5002(33.30)$ & $3761(33.20)$ & $1241(28.40)$ & \\
\hline$>16$ years & $382(2.50)$ & $298(2.60)$ & $84(1.90)$ & \\
\hline \multicolumn{5}{|l|}{ Years of Maternal education } \\
\hline$<9$ years & $1420(10.60)$ & $889(7.10)$ & $531(11.80)$ & \multirow[t]{4}{*}{$<0.04^{* *}$} \\
\hline $9-12$ years & $7971(53.90)$ & $5579(47.90)$ & 2392(53.30) & \\
\hline $12-16$ years & 6383(33.10) & $4906(42.10)$ & 1477(33.00) & \\
\hline 16 years & $359(2.40)$ & $275(2.40)$ & $84(1.90)$ & \\
\hline Socio-economic status variables & Total N(\%) & Primary schoolchildren $\mathrm{N}(\%)$ & Secondary schoolchildren N (\%) & $P$ value \\
\hline \multicolumn{5}{|c|}{ Home square meters $\left(\mathrm{m}^{2}\right) /$ persons living at home } \\
\hline$<50$ & $16,878(98.00)$ & $11,944(96.60)$ & $4934(100.00)$ & \multirow[t]{3}{*}{$<0.001^{*}$} \\
\hline $50-75$ & $395(2.00)$ & $395(3.00)$ & & \\
\hline $76-130$ & $26(<0.10)$ & $26(0.20)$ & & \\
\hline \multicolumn{5}{|l|}{ Number of cars } \\
\hline 0 & $934(5.30)$ & $617(4.90)$ & $317(6.30)$ & \multirow[t]{4}{*}{$0.19^{* *}$} \\
\hline 1 & $8705(49.10)$ & $645(48.50)$ & $2560(50.70)$ & \\
\hline 2 & $7364(41.60)$ & $5427(42.80)$ & 1937(38.40) & \\
\hline$\geq 3$ & $717(4.00)$ & $482(3.80)$ & 235(4.70) & \\
\hline \multicolumn{5}{|l|}{ Home property } \\
\hline Rent & 1821(10.30) & 1029(8.10) & $792(15.40)$ & \multirow[t]{2}{*}{$0.14^{*}$} \\
\hline Owned & $15,879(89.70)$ & $11,746(91.90)$ & 4133(80.30) & \\
\hline
\end{tabular}

*The Chi-square test was used to calculate the $p$-value

**The Mann-Whitney test was used to calculate the $p$-value 
Table 2 Descriptive statistics and statistical tests results for sociodemographic characteristics of children attending primary and secondary schools

\begin{tabular}{|c|c|c|c|c|}
\hline Variables & Total N(\%) & Primary schoolchildren N(\%) & Secondary schoolchildren N (\%) & $p$ value \\
\hline \multicolumn{5}{|l|}{ Gender } \\
\hline Girl & $9489(50.40)$ & $6621(50.50)$ & $2868(51.00)$ & \multirow[t]{2}{*}{$0.65^{*}$} \\
\hline Boy & $9332(49.60)$ & $6483(49.50)$ & $2849(49.00)$ & \\
\hline \multicolumn{5}{|c|}{ Participation in OPA } \\
\hline Yes & $10,519(57.60)$ & $8171(62.3)$ & $2348(44.60)$ & \multirow[t]{2}{*}{$<0.001^{*}$} \\
\hline No & $7747(42.40)$ & $4948(37.7)$ & $2799(55.40)$ & \\
\hline \multicolumn{5}{|l|}{ BMI } \\
\hline Underweight & $427(2.50)$ & $57(0.50)$ & $370(7.40)$ & \multirow[t]{4}{*}{$<0.001^{* *}$} \\
\hline Normal weight & $10,660(62.90)$ & $7607(63.40)$ & $3053(61.00)$ & \\
\hline Overweight & $4296(25.30)$ & $3057(25.80)$ & $1235(24.00)$ & \\
\hline Obese & $1573(9.30)$ & $1229(10.40)$ & $339(6.60)$ & \\
\hline \multicolumn{5}{|c|}{ Father's participation in OPA } \\
\hline Yes & $8821(48.30)$ & $6628(50.50)$ & $2193(42.60)$ & \multirow[t]{2}{*}{$<0.001^{*}$} \\
\hline No & $9443(51.90)$ & $6491(49.50)$ & 2952(57.40) & \\
\hline \multicolumn{5}{|c|}{ Mother's participation in OPA } \\
\hline Yes & $9957(56.30)$ & $7038(53.60)$ & 1646(32.00) & \multirow[t]{2}{*}{$0.03^{*}$} \\
\hline No & $7727(43.70)$ & $6081(46.40)$ & 2919(56.70) & \\
\hline \multicolumn{5}{|l|}{ Geographic Area } \\
\hline Rural & $5510(30.20)$ & $4267(32.50)$ & $1243(24.10)$ & \multirow[t]{3}{*}{$0.20^{* *}$} \\
\hline Semi Urban & 4797 (26.20) & $3843(29.30)$ & $954(18.50)$ & \\
\hline Urban & 7957 (43.60) & 5009(38.20) & 2948(57.40) & \\
\hline
\end{tabular}

*The Chi-square test was used to calculate the $p$-value

**The Mann-Whitney test was used to calculate the $p$-value

with primary schoolchildren being more likely to be overweight ( $25.8 \%$ vs $24.0 \%)$ and obese $(10.4 \%$ vs $6.6 \%)$ and not underweight $(0.5 \%$ vs $7.4 \%)$ compared to secondary schoolchildren.

Highly significant differences were also observed in parents' participation in OPA between primary and secondary schools. Furthermore, there was a dramatic decrease in parents' OPA from primary to secondary school and these differences were highly significant, especially in case of father's participation in an OPA $(\mathrm{p}<$ $0.001)$.

\section{Univariate models}

Influence of BMI category.

Underweight children participated more frequently in an OPA ( $75.8 \%$ vs $52.0 \%$ in normal weight children) than normal weight children (Fig. 2), although this association isn't statistically significant $(p=0.70)$. On the other hand, underweight adolescents were 1.34 times (95\%CI: $1.11-$ 1.61) more likely to not participate in an OPA than normal weight children.

Overweight primary schoolchildren participated less frequently in an OPA than normal weight children $(39 \%$ vs $37 \%$ respectively).
- Results for overweight secondary schoolchildren pointed in the same direction, (56\% of overweight adolescents vs $52 \%$ of normal weight adolescents), but none of these differences was statistically significant $(p>0.05)$.

Obese primary schoolchildren were 1.19 times (95\% CI:1.05-1.34) more likely not to participate in an OPA (46\% vs $37 \%$ respectively) than normal weight children. Also, obese secondary school children were 1.16 times (95\% CI: $1.01-1.44)$ more likely not to participate in an OPA, ( $55 \%$ vs $52 \%$ respectively), than normal weight children (Fig. 2).

\section{Influence of sociodemographic factors}

Table 3 indicates the significant results $(p<0.10)$, at least for one school level, from univariate analysis of the above mentioned socio-demographic and demographic characteristics associated with organized activity participation, by school level.

Significant associations in both school level groups were observed for gender and father's and mother's participation in an OPA. Age is at risk because it's a highly significant $p$ value. $(p<0.001)$ for non-participation in an OPA. Participation in sports tends to decrease with age even within primary school children. 


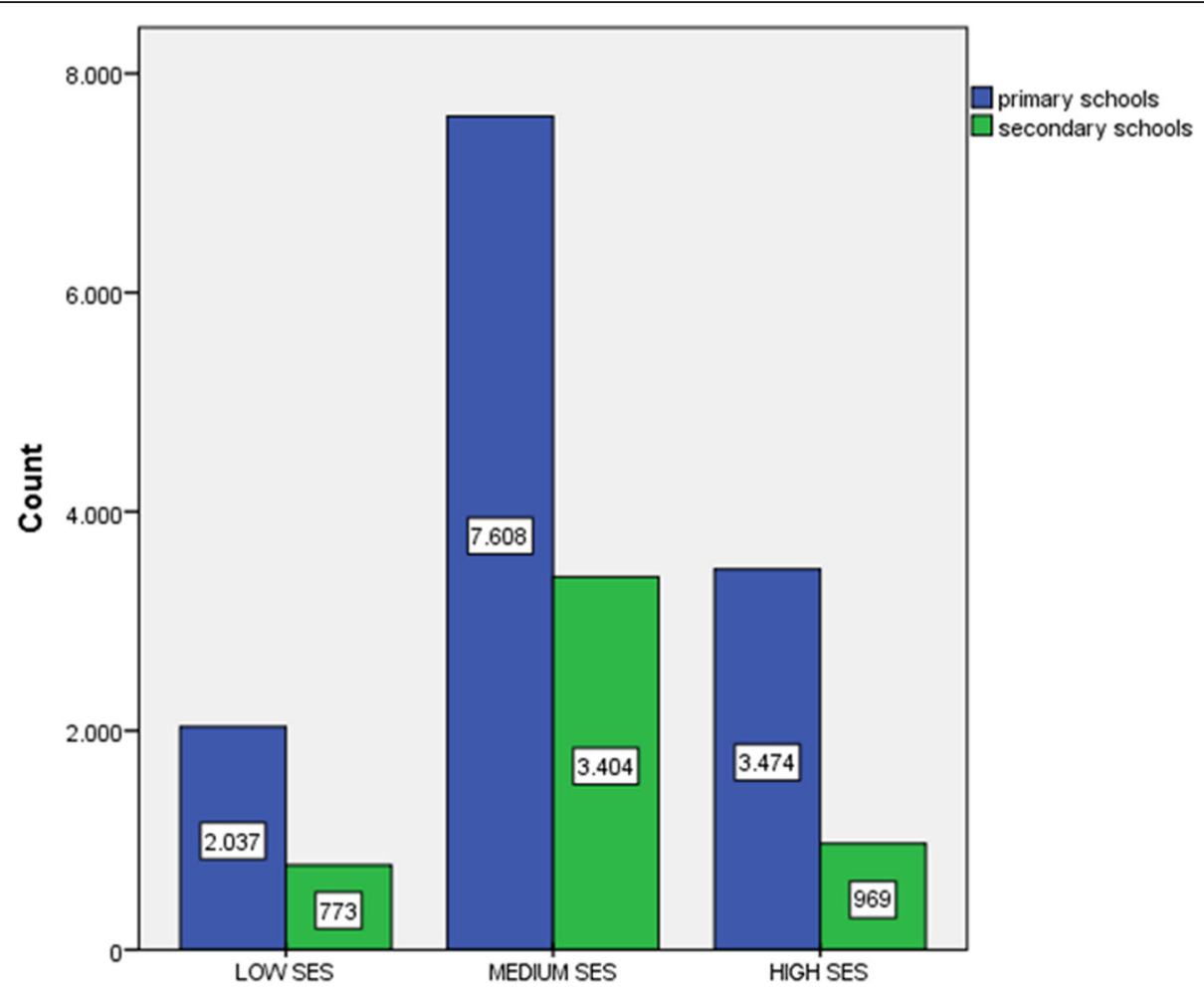

Fig. 1 SES distribution by School type

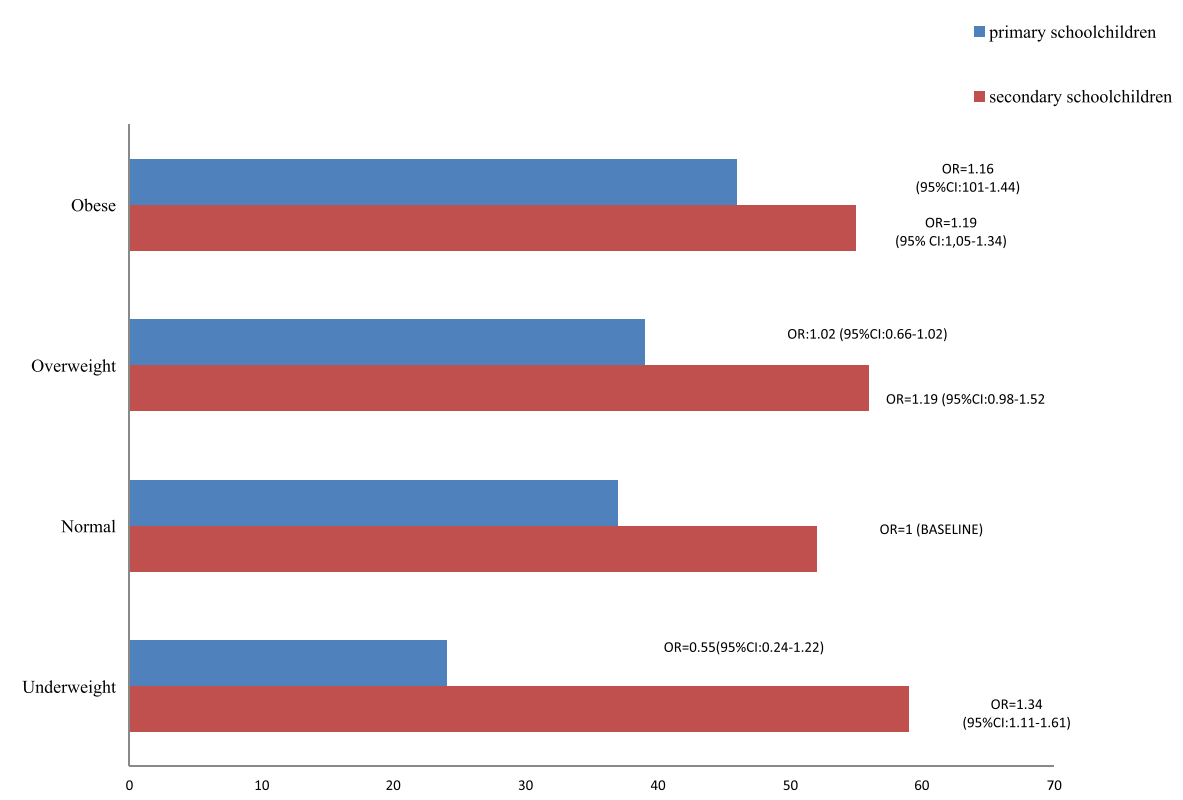

Fig. $2 \%$ Proportion of children and adolescents with no reported organized sports participation for each BMI category and Odds Ratios (baseline = normal weight) 
As can be seen on Table 3, boys were more likely to participate in OPA than girls at both school levels. Regarding socio-economic status, children with low socioeconomic levels participated less frequently in OPA than children with a medium/high one and this association was highly significant $(\mathrm{p}<0.001)$. Furthermore, regarding the impact of the area of residence, secondary schoolchildren living in an urban area participated more frequently in an organized physical activity than those living in a rural or semi-urban area in both school levels and these differences are highly significant $(\mathrm{p}<0.001)$.

\section{Interaction effects}

Significant interactions $(p=0.03)$ were observed between father's and mother's participation in OPA in primary school children. (unadjusted OR: 1.16; 95\% CI: $1.05-$ 1.40). Statistical interactions among all other potential covariates were tested, but none was significant.

\section{Multivariate models}

Table 4 shows the final results from the multivariate analysis of the factors associated with OPA at $\alpha=5 \%$. After adjustments for all potential covariates, being male and having a high SES seems to favor participation in an OPA in both school levels but to a different extent. Primary school children with low SES were 2.30 (95\% CI: 2.05-2.58) times more likely not to participate in OPA than other SES categories. Secondary schoolchildren were 1.49 (95\% CI:1.31-1.70) times more likely not to participate in OPA than other SES categories. The father's or mother's participation in physical activity remained significant in a multivariate model for both school levels $(p<0.05)$. The interaction between the father's and mother's participation in OPA no longer affected primary schoolchildren's participation in OPA in the multivariate model $(p=0.63)$. Also, the geographic area remained significant only for adolescents $(p=$ 0.001). Being adolescent and residing in a rural area remained a significant factor for non-participation in OPA. Different categories of BMI by school level were associated with no participation in OPA. Being adolescent and underweight $(p=0.04)$ or a primary school pupil and obese $(p=0.04)$, increases the odds for nonparticipation in OPA.

Age remained a risk factor for non-participation in OPA within primary schoolchildren $(p=0.02)$. As a child grows older, from the first grades of primary school to the upper ones, they participated less frequently in OPA.

\section{Discussion}

Developing of a better understanding regarding the magnitude of effect of potential factors associated with participation in OPA. BMI could affect participation through its effects on performance motivation and confidence. Longitudinal study has addressed the question whether there is an association between OPA and BMI and to which direction if there is one. They concluded that there is a bidirectional relationship, meaning that past participation in oPA predicts BMI and past BMI predicts participation in OPA [26]. It has been advised by recent guidelines as an intervention for overweight and obese children and adolescents [27].

This large cohort, nationwide study among school-age children in Greece showed that there was a high percentage of inactive children and adolescents, and this

Table 3 Significant results for at least one school level from univariate analysis and interactions effects analysis of covariates associated with prevalence of OPA in the primary and secondary schools children, Greece

\begin{tabular}{|c|c|c|c|c|}
\hline \multirow[b]{2}{*}{ Variables } & \multicolumn{2}{|l|}{$P$ value } & \multicolumn{2}{|l|}{ OR $(95 \% \mathrm{Cl})$} \\
\hline & $\begin{array}{l}\text { Primary } \\
\text { schoolchildren }\end{array}$ & $\begin{array}{l}\text { Secondary } \\
\text { schoolchildren }\end{array}$ & $\begin{array}{l}\text { Primary } \\
\text { schoolchildren }\end{array}$ & $\begin{array}{l}\text { Secondary } \\
\text { schoolchildren }\end{array}$ \\
\hline Gender (males vs females) & $<0.001$ & $<0.001$ & $1.25(1.16-1.34)$ & $1.16(1.04-1.30)$ \\
\hline Father's participation in OPA (yes vs no) & $<0.001$ & $<0.001$ & $1.51(1.41-1.62)$ & $1.24(1.10-1.39)$ \\
\hline $\begin{array}{l}\text { Mother's participation in OPA } \\
\text { (yes vs no) }\end{array}$ & $<0.001$ & 0.01 & $1.32(1.18-1.47)$ & $\begin{array}{l}1.176 \\
(1.05-1.32)\end{array}$ \\
\hline Obesity (vs normal weight) & 0.03 & 0.04 & $0.83(0.74-0.95)$ & $0.87(0.77-0.98)$ \\
\hline Overweight (vs normal weight) & 0.17 & 0.06 & $0.84(0.66-1.02)$ & $0.80(0.64-1.01)$ \\
\hline Underweight (vs normal weight) & 0.70 & 0.03 & $1.82(0.81-4.16)$ & $0.75(0.62-0.90)$ \\
\hline Geographic area (Urban vs rural) & 0.32 & $<0.001$ & $0.92(0.52-1.04)$ & $1.60(1.486-1.713)$ \\
\hline Low SES (vs other categories) & $<0.001$ & $<0.001$ & $0.44(0.39-0.49)$ & $0.68(0.56-0.80)$ \\
\hline High SES (vs other categories) & $<0.001$ & $<0.001$ & $1.84(1.68-2.03)$ & $1.12(1.09-1.16)$ \\
\hline Age (6-12 years vs $12-15$ years) & $<0.001$ & 0.54 & $0.87(0.81-0.94)$ & $0.82(0.43-1.56)$ \\
\hline $\begin{array}{l}\text { Father's participation in OPA * Mother's participation } \\
\text { in OPA }\end{array}$ & 0.03 & 0.06 & $1.16(1.05-1.40)$ & $1.25(0.99-1.46)$ \\
\hline
\end{tabular}


Table 4 Multivariate analysis of covariates associated with OPA prevalence in the primary and secondary schools children, Greece

\begin{tabular}{|c|c|c|c|c|}
\hline \multirow[b]{2}{*}{ Variables } & \multicolumn{2}{|l|}{$P$ value } & \multicolumn{2}{|l|}{$\mathrm{OR}(95 \% \mathrm{Cl})^{\mathrm{a}}$} \\
\hline & Primary schoolchildren & Secondary schoolchildren & Primary schoolchildren & Secondary schoolchildren \\
\hline Gender (males vs females) & $<0.001$ & 0.01 & $1.25(1.15-1.37)$ & $1.17(1.05-1.30)$ \\
\hline Father's participation in OPA (yes vs no) & $<0.001$ & 0.03 & $1.52(1.310-1.770)$ & $1.16(1.01-1.32)$ \\
\hline Mother's participation in OPA (yes vs no) & $<0.001$ & 0.02 & $1.79(1.31-1.77)$ & $1.22(1.03-1.43)$ \\
\hline Obesity (vs normal weight) & 0.036 & 0.37 & $0.75(0.58-0.98)$ & $0.91(0.74-1.12)$ \\
\hline Underweight (vs normal weight) & $N S^{a}$ & 0.04 & NS & $0.76(0.59-0.99)$ \\
\hline Geographic area (Urban vs rural) & NS & $<0.01$ & NS & $1.22(1.09-1.36)$ \\
\hline Low SES (vs other categories) & $<0.001$ & $<0.001$ & $0.65(0.58-0.73)$ & $0.67(0.59-0.77)$ \\
\hline $\begin{array}{l}\text { High } \\
\text { SES (vs other categories) }\end{array}$ & $<0.001$ & $<0.01$ & $1.38(1.29-1.48)$ & $1.36(1.11-1.36)$ \\
\hline Age (6-12 years vs $12-15$ years) & 0.03 & NS & $0.90(0.83-0.98)$ & NS \\
\hline
\end{tabular}

The initial logistic models included, in addition to these, the categorical variable overweight (vs normal weight) for secondary schoolchildren and the interaction between father and mother's participation in OPA in primary school children ${ }^{a}$ Non significant

was affected by age, gender, BMI category, parent' level of physical activityand socioeconomic factors.

BMI emerged as an important factor influencing participation in OPA. Weight status was significantly related to OPA, particularly for primary schoolchildren. Healthy-weight primary schoolchildren were more active than obese primary schoolchildren. As obesity is the result of a positive calorie balance it is contemplated that obese children are less physically active. Cadogan et al. [6] found an association between being overweight or obese and not achieving high levels of physical activity in a sample of Irish children. Similarly, Tambalis et al. [28], in a large epidemiological study of 8 to 9 year-old children, found a negative association between excess weight and performance in aerobic and motor fitness tests, but not in upper body strength. This could be related with the feelings of incompetence in physical activities, or unfavorable self-perceptions derived from social comparison with normal-weight peers [29]. Although some studies, as the Australian one [8] did not find any association between organized sports participation and BMI [7], the results of the present study are in agreement with previous findings showing an association of organized sports participation with BMI category. This study, further shows that this association remains significant even after controlling for age and family-related confounding variables. These results suggest that OPA participation is an important aspect when examining obesity, even at this young age. Regular participation in organized sports, already reduced the odds for being obese by almost $33 \%$ in primary schoolchildren. As this is a cross sectional study we cannot assert causality from the results of this study. It is not possible to understand whether this is a contributing factor to the development of overweight and obesity due to positive caloric balance or this is a consequence of the obesity as obese children are generally less competent in sports as a result of physical limitations or poor self-esteem. This is an important issue that needs to be dealt with and OPA should not only be addressed to strong athletes but offer the opportunity to all children to exercise in a noncompetitive manner.

An interesting and underreported finding is that underweight adolescents participate less in organized sports. In a sample of Polish adolescents (14-16 years old), found that underweight and overweight boys were characterized by significantly lower levels of physical activity compared to normal weight participants [30]. Vella et al. [8],, reported lower levels of sports participation among underweight adolescents in Australia and suggested that a possible explanation could be their low muscle mass, making them less successful when competing in sports, compared to normal-weight children. Nevertheless, the association between reduced sports participation, physical activity, and BMI category, is bidirectional and it is difficult to draw causality conclusions. An important association that emerged from this studyis the influence of the age group, as participation in OPA decreases dramatically from primary to high school: A large decrease in sports participation was noted as children went through adolescence. Lower levels of participation in OPA with increasing age were also reported for a multinational sample of British adolescents [31] and in Australian youth but to a lesser degree [32]. Possible causes for this decline in physical activity are changes in personal preferences, limited free time due to increased school obligations, increased need for socializing and going out with friends, body changes altering success rates in competitive sports.

With respect to gender, lower levels of sports participation among girls as compared to boys have been well established [31, 33, 34] and especially in OPA [7]. 
Results of our study are in the same direction. A possible explanation for the lower level of sports participation and physical activity in females could be related with the stereotype and gender roles set by society, which are internalized by early childhood through social influences by parents and grand parents and could determine perceived competence [35].

. Parents as a role model is a significant contributor to children's involvement in OPA. Parents who are physically active, appeared to have a strong role in supporting children to be more active in both school levels. A number of studies support these findings. Cross-sectional researches in preschool and school children and their parents showed that parents whoare physically active, are more likely to support their children's engagement in physical activity [36, 37]. Possible mechanisms for the relationship between parents' and child's activity levels include the parents' serving as role models, enhancement and support by active parents of their child's participation in physical activity, and genetically transmitted factors that predispose the child to be more physically active [38].Furthermore, the Greek family fits the 'Mediterranean model'and consequently, it shares similar socio-demographic characteristics with other Mediterranean countries, meaning that traditional values and roles (marriage, family ties) are prevalent [39]. Thus, parents have a sound effect on their children's every day habits.

The importance of socioeconomic status in influencing the participation in organized physical activity has been recognized in the present study, of Greek students.

These results may be partly explained by the social processes which occurred in Greece as a result of:

1. The financial crisis, when a significant number of pupils

transferred from private to public schools. The number of students in private education decreased to 70.7 thousand in 2015 from 94.2 thousand in 2000 and 93.4 thousand in 2009. Private schools lost more than 20,000 students $(-9.5 \%)$. It was observed a downward trend in higher income scales and a corresponding quadrupling of the lower income category [40].

2. The increasing educational level of Greeks and Greek women in particular [40, 41]

Our findings that socioeconomic status is a significant predictor of participation in OPA in both school levels, are consistent with reports for children and adolescents of other countries [17, 42-45]. Parents from higher socioeconomic classes will probably encourage their children to participate in OPA to a greater extent than parents from lower socioeconomic classes. Such findings may be explained by the fact that some OPA are not easily accessible by lower socioeconomic classes because of the lack of transport or money.
Additionally, the area of residence impacts on the level of participation in OPA. The results of this study showed higher level of participation in OPA of the residents of urban settings. This finding contrasts with previous reports of other countries stating that children residing in cities engage in OPA much less as compared to their peers residing in rural areas $[8,15,46,47]$. At this point, it should be noted that the lack of infrastructure in rural areas, and the small number of inhabitants, preclude the access of adolescents to gyms and sports facilities.

Limitations of the present study arethe self-reporting of information regarding sports participation which is a source of bias and the cross-sectional design which does not allow for causality conclusions. Thus, temporal relationship between OPA participation and covariates is unknown. Longitudinal data are necessary to further unravel the complex interplay between the endogenous variable and the above mentioned covariates. Strong points of the study are the representative sample, the nationwide participation, the large number of the cohort that increase the external validity of the study.

\section{Conclusions}

Participation in OPA decreases with age, the greatest difference being observed after transition from primary to secondary school. Significant factors associated with the lack of physical activity were: the low socioeconomic status, the female gender, the BMI category (obese and underweight, for primary and secondary schools respectively), the parents' non participation in OPA, being adolescent and residing in a rural area. This study provides additional evidence that the family constitutes an important socializing agent and role model regarding OPA. Intervention programs' designers are encouraged to develop methods that will aim to parental motivation in order to improve OPA participation of all family members. Parents provide a target group for interventions, especially at early school ages, in order to understand the importance and be motivated to promote the importance of PA in their children either by acting as model behaviour or by supporting their child's active participation to sport activities.

Covariates that are not considered modifiable, such as age and gender, can be used to guide targeted interventions and policies.

Finally, a better understanding of trends in children's physical activity patterns within different weight status, SES areas and regional environments are the challenges faced by municipalities. The delivery of increased hours of physical education and sports incorporated into school daily program can possibly eliminate the impact of SES inequalities. Longitudinal studies will further elucidate these issues. 


\section{Abbreviations}

BMI: Body Mass Index; OR: Odds Ratio; OPA: Organized Physical Activity

\section{Acknowledgements}

The authors are indebted to all research team members, as well as to the parents/caregivers and children for their participation in the study. Also, the authors thank the editors and reviewers for their constructive critique and positive review of this paper.

\section{Authors' contributions}

VC, DK, GB, EV, TP, YM, FK, AH and SM contributed to the design of the study, data collection and data management. VC lead the statistical analyses and the writing of the manuscript with the contribution and input from all authors. All authors critically reviewed and approved the final version of the manuscript for publication.

\section{Funding}

This research was part of the "Hellenic National Action Plan for the Assessment, Prevention and Treatment of childhood obesity. Actions for exercise and physical activity". (MIS 301205) which was co-financed by the European Union (European Social Fund - ESF) and Greek national funds through the National Strategic Reference Framework (NSRF). The funding body/bodies had approved the design of the study and supervised that the methodology and timetable were followed as planned. They had no involvement in the collection, analysis, and interpretation of data or in writing of the manuscript.

\section{Availability of data and materials}

The datasets generated during and/or analysed during the current study are available from the corresponding author on reasonable request.

\section{Ethics approval and consent to participate}

All procedures performed in studies involving human participants were in accordance with the ethical standards of the institutional and/or national research committee and with the 1964 Helsinki declaration and its later amendments or comparable ethical standards. The protocol was approved by the Ethics Committee of the Hellenic Data Protection Authority, the Minister of Health and the Minister of Education. Informed consent was obtained from all individual participants included in the study.

\section{Consent for publication}

Not applicable.

\section{Competing interests}

No competing financial interests exist.

\section{Author details}

'Laboratory of Statistical Modelling and Educational Technology in Public and Environmental Health- sepeh.lab, Department of Public and Community Health, University of West Attica, 28 Saint Spyridonos str, 12243 Egaleo, Greece. ${ }^{2}$ Department of Endocrinology, Children's Hospital P. \& A. Kyriakou, Thibon \& Levadeias str, Ampelokipoi T.K, 11527 Athens, Greece. ${ }^{3}$ School of Physical Education \& Sports Science, National and Kapodistrian University of Athens, 41, Ethnikis Antistaseos str., 17237 Daphne, Athens, Greece. ${ }^{4}$ Department of Hygiene, Epidemiology and Medical Statistics, School of Medicine, National and Kapodistrian University of Athens, 75 Mikras Asias str, 11527 Goudi, Greece. ${ }^{5}$ Department of Nutrition \& Dietetics, School of Health Science \& Education, Harokopio University, 70, El Venizelou Ave 17671 Kallithea, Athens, Greece.

Received: 29 December 2019 Accepted: 5 August 2020

Published online: 22 October 2020

\section{References}

1. Ruotsalainen $H$, Kyngas $H$, Tammelin $T$, et al. Systematic review of physical activity and exercise interventions on body mass indices, subsequent physical activity and psychological symptoms in overweight and obese adolescents. J Adv Nurs. 2015:71:2461-77.

2. Tajik E, Abd Latiff L, Adznam SN, et al. A study on level of physical activity, depression, anxiety and stress symptoms among adolescents. J Sports Med Phys Fitness. 2017:57:1382-7.
3. Paz-Krumdiek M, Rodriguez-Velez SG, Mayta-Tristan P, et al. Association between sitting time and obesity: a population-based study in Peru. Nutrition Dietetics. 2020;772:189-95.

4. Hong I, Coker-Bolt P, Anderson KR, et al. Relationship Between Physical Activity and Overweight and Obesity in Children: Findings From the 2012 National Health and Nutrition Examination Survey National Youth Fitness Survey. Am J Occup Ther. 2016;70:7005180060p1-8.

5. WHO Guidelines Approved by the Guidelines Review Committee. Global Recommendations on Physical Activity for Health. Geneva: World Health Organization Copyright (c) World Health Organization; 2010. p. 2010.

6. Cadogan SL, Keane E, Kearney PM. The effects of individual, family and environmental factors on physical activity levels in children: a crosssectional study. BMC Pediatr. 2014;14:107.

7. Marques A, Ekelund U, Sardinha LB. Associations between organized sports participation and objectively measured physical activity, sedentary time and weight status in youth. J Sci Med Sport. 2016;192:154-57.

8. Vella SA, Cliff DP, Okely AD, et al. Associations between sports participation, adiposity and obesity-related health behaviors in Australian adolescents. Int J Behav Nutr Phys Act. 2013;10:113.

9. Silva $G$, Andersen LB, Aires $L$, et al. Associations between sports participation, levels of moderate to vigorous physical activity and cardiorespiratory fitness in childrenand adolescents. J Sports Sci. 2013;31: 1359-67.

10. Bengoechea EG, Sabiston CM, Ahmed R, Farnoush M. Exploring links to unorganized and organized physical activity during adolescence: the role of gender, socioeconomic status, weight status, and enjoyment of physical education. Res Q Exerc Sport. 2010;81(1):7-16.

11. MacKenzie J, Brunet J, Boudreau J, lancu HD, Bélanger M. Does proximity to physical activity infrastructures predict maintenance of organized and unorganized physical activities in youth? Prev Med Rep. 2015;2:777-82.

12. Lasheras $L$, Aznar $S$, Merino B, et al. Factors associated with physical activity among Spanish youth through the National Health Survey. Prev Med. 2001; 32:455-64.

13. Sallis JF. Epidemiology of physical activity and fitness in children and adolescents. Crit Rev Food Sci Nutr. 1993;33:403-8.

14. Cooper AR, Goodman A, Page AS, et al. Objectively measured physical activity and sedentary time in youth: the International children's accelerometry database (ICAD). Int J Behav Nutr Phys Act. 2015;12:113.

15. Sember V, Morrison SA, Jurak G, et al. Differences in physical activity and academic performance between urban and rural schoolchildren in Slovenia. Montenegrin J Sports Sci Med. 2018;7:67.

16. Solomon-Moore E, Toumpakari Z, Sebire SJ, et al. Roles of mothers and fathers in supporting child physical activity: a cross-sectional mixedmethods study. BMJ Open. 2018;8:e019732.

17. Veselska Z, Geckova AM, Reijneveld SA, et al. Socio-economic status and physical activity among adolescents: the mediating role of self-esteem. Public Health. 2011;125:763-8.

18. Deforche B, Van Dyck D, Deliens T, et al. Changes in weight, physical activity, sedentary behaviour and dietary intake during the transition to higher education: a prospective study. Int J Behav Nutr Phys Act. 2015;12:16.

19. Tufféry S. Data mining and statistics for decision making. Wiley. 2011; 1460-642.

20. Cole TJ, Lobstein T. Extended international (IOTF) body mass index cut-offs for thinness, overweight and obesity. Pediatr Obes. 2012;7:284-94.

21. Carayanni V, Vlachopapadopoulou E, Psaltopoulou T, et al. Validity and reliability of three new instruments for parents and children assessing nutrition and physical activity behaviors, environment and knowledge and health in childhood and adolescence in Greece during the economic recession: data from the national action plan for public health (MIS301205). Value Health. 2016;19:A395.

22. Moschonis G, Mavrogianni C, Karatzi K, et al. Increased physical activity combined with more eating occasions is beneficial against dyslipidemias in children. The healthy growth study. Eur J Nutr. 2013;52:1135-44

23. Talaei M, Rabiei K, Talaei Z, et al. Physical activity, sex, and socioeconomic status: a population based study. ARYA Atherosclerosis. 2013;9:51.

24. Hilbe JM. Practical guide to logistic regression. Chapman and Hall/CRC; 2016. p. 144-8.

25. Hilbe JM. Logistic regression models. Chapman and hall/CRC; 2009. p. 63-7.

26. Cairney J, Veldhuizen S. Organized sport and physical activity participation and body mass index in children and youth: A longitudinal study. Prev Med Rep. 2017;6:336-8. 
27. Styne DM, Arslanian SA, Connor EL, et al. Pediatric obesity—assessment, treatment, and prevention: an Endocrine Society clinical practice guideline. J Clin Endocrinol Metab. 2017;102:709-57.

28. Tambalis KD, Panagiotakos DB, Psarra G, et al. Inverse but independent trends in obesity and fitness levels among Greek children: a time-series analysis from 1997 to 2007. Obesity Facts. 2011;4:165-74.

29. Bergh $\mathbb{I H}$, Bjelland $M$, Grydeland M, et al. Mid-way and post-intervention effects on potential determinants of physical activity and sedentary behavior, results of the HEIA study - a multi-component school-based randomized trial. Int J Behav Nutr Phys Act. 2012;9:63.

30. Kantanista A, Osinski W. Underweight in 14 to 16 year-old girls and boys: prevalence and associations with physical activity and sedentary activities. Ann Agric Environ Med. 2014;21(1).

31. Brodersen NH, Steptoe A, Boniface DR, et al. Trends in physical activity and sedentary behaviour in adolescence: ethnic and socioeconomic differences. Br J Sports Med. 2007;41:140-4.

32. Telford RM, Telford RD, Cochrane T, et al. The influence of sport club participation on physical activity, fitness and body fat during childhood and adolescence: the LOOK longitudinal study. J Sci Med Sport. 2016;19:400-6.

33. Charlton R, Gravenor MB, Rees A, et al. Factors associated with low fitness in adolescents--a mixed methods study. BMC Public Health. 2014;14:764.

34. Santiago S, Cuervo M, Zazpe I, et al. Weight status, dietary habits and physical activity among 6-12 year-old children in Castile-La Mancha. Anales de pediatria. 2014:80:89-97.

35. Chalabaev A, Sarrazin P, Fontayne P, et al. The influence of sex stereotypes and gender roles on participation and performance in sport and exercise: review and future directions. Psychol Sport Exerc. 2013;14:136-44.

36. Klesges RC, Eck LH, Hanson CL, et al. Effects of obesity, social interactions, and physical environment on physical activity in preschoolers. Health Psychol. 1990;9:435.

37. Welk GJ, Wood K, Morss G. Parental influences on physical activity in children: an exploration of potential mechanisms. Pediatr Exerc Sci. 2003;15: 19-33.

38. Moore LL, Lombardi DA, White MJ, et al. Influence of parents' physical activity levels on activity levels of young children. J Pediatr. 1991;118:215-9.

39. D'Agostino M, Samuel NO, Sarol MJ, et al. Open data and public health. Rev Panam Salud Publica. 2018;42:e66.

40. IOBE. Crisis, demographic change and impact on education (in Greek), available at: http://iobe.gr/docs/research/RES_05_F_17122018_REP.pdf. 2018.

41. Eurostat. Tertiary education statistics available at:https:/ec.europa.eu/ eurostat/statistics-explained/index.php/Tertiary_education_ statistics\#Participation_of_men_and_women_in_tertiary_education. 2017.

42. Stephens T, Jacobs DR Jr, White CC. A descriptive epidemiology of leisuretime physical activity. Public Health Rep. 1985;100:147.

43. Dregval L, Petrauskienè A. Associations between physical activity of primary school first-graders during leisure time and family socioeconomic status. Medicina. 2009:45:549.

44. Santos MP, Oliveira J, Ribeiro JC, et al. Active travel to school, BMI and participation in organised and non-organised physical activity among Portuguese adolescents. Prev Med. 2009:49:497-9.

45. Biddle SJ, Atkin AJ, Cavill N, et al. Correlates of physical activity in youth: a review of quantitative systematic reviews. Int Rev Sport Exerc Psychol. 2011; 4:25-49.

46. Loucaides CA, Chedzoy SM, Bennett N. Differences in physical activity levels between urban and rural school children in Cyprus. Health Educ Res. 2004; 19:138-47.

47. Joens-Matre RR, Welk GJ, Calabro MA, et al. Rural-urban differences in physical activity, physical fitness, and overweight prevalence of children. J Rural Health. 2008;24:49-54.

\section{Publisher's Note}

Springer Nature remains neutral with regard to jurisdictional claims in published maps and institutional affiliations.

Ready to submit your research? Choose BMC and benefit from:

- fast, convenient online submission

- thorough peer review by experienced researchers in your field

- rapid publication on acceptance

- support for research data, including large and complex data types

- gold Open Access which fosters wider collaboration and increased citations

- maximum visibility for your research: over $100 \mathrm{M}$ website views per year

At BMC, research is always in progress.

Learn more biomedcentral.com/submissions 